\title{
El teatro escrito del cambio de siglo: \\ explosión, ausencias y rupturas
}

\section{Diego La Hoz}

Espacio Libre

\section{RESUMEN}

Este ensayo presenta un mapa panorámico de las distintas tendencias y temáticas presentes en la nueva dramaturgia peruana.

\section{PALABRAS CLAVE}

Perú, creación colectiva, teatro de grupo, nueva dramaturgia peruana.

\section{ABSTRACT}

This essay presents a panoramic map of the different trends and themes present in the new Peruvian play-writing.

\section{KEY WORDS}

Peru, collective creation, theater group, new Peruvian play-writing.

En los últimos 20 años, hablar sobre dramaturgia peruana, más allá del análisis académico, me conduce a dar testimonio de lo que pude experimentar en carne propia como espectador activo de un teatro que celebraba entusiasta (y a la vez desconcertado) el cambio de siglo. Pero el teatro es eso. La posibilidad de producir ese «algo» desde un constante desconcierto.

Lo primero que me viene a la mente es la palabra explosión. jBoom! Inevitable onomatopeya de un grito parecido al cuadro de Munch. Explosión como proceso de (re)valoración del texto dramático. Algo estaba pasando desde la mirada quieta y silenciosa de los nuevos creadores que, como yo, transitábamos huérfanos por el camino. No teníamos padres. En todo caso, estaban ausentes. Aquellos posibles referentes estaban en algún lugar invisible y los otros, con la cabeza escondida en alguna tierra 
extraña. Sus luchas ya no eran inspiradoras o parecía más bien que no había razón para seguir luchando. Lo bueno de tener un «padre» es que se puede prolongar una tradición cultural o asesinarlo sin miedo para que aparezcan otras formas de hablar de nosotros.

En la historia republicana del Perú nuestro país nunca ha podido consolidar un "proyecto» como nación. Nunca hemos sostenido un sistema democrático de largo alcance. Hoy somos una democracia de apenas 13 años. Por lo tanto, cualquier intento de defenderla siempre es débil y precario. Nunca la cultura ha tenido un lugar de privilegio porque el hambre, la salud y la educación públicas siempre aparecen como tareas urgentes. ¡Y lo son! Con esto no quiero decir que las necesidades urgentes sean responsables de que la cultura se encuentre en el último peldaño de prioridades, claro está. ¿Quién piensa en ella cuando un tercio del país vive en extrema pobreza y la mayoría no accede a servicios dignos de salud y educación? Lamentablemente, esto último forma parte de nuestra cultura. ¡Qué paradoja tan dolorosa! En resumen, a lo que me refiero es que, si no tenemos un «proyecto» como país, la cultura tendrá que construir sus propios espacios de desarrollo. Y ellos, sin duda, serán subjetivos, efímeros y desarticulados del otro con quien se habita. Claramente, esos espacios propios se aplican al teatro. Sobre todo al de cambio de siglo. En las décadas de 1960 y 1970 se intentó darle una nueva mirada a nuestro teatro desde conceptos de grupalidad, creación colectiva y énfasis en lo corporal. Se trabajaba con el otro buscando la función social del teatro. Había ideales comunes, sueños de transformación y militancia en aquello que nos reunía como objetivo. En los años 80 , en medio de la durísima guerra interna que tuvimos, la creación se volvió individual y se replanteó la relación con la escena en sí misma. Aparecieron las individualidades como roles delimitados (autor/director/actor) para articular y fragmentar la nueva dinámica escénica. El ejercicio de lo colectivo aportó a la gestación de nuevos dramaturgos que, en su mayoría, habían explorado sus habilidades en diversos grupos teatrales y que ahora continúan produciendo de manera individual. Nombro a algunos de ellos: Alfonso Santisteban, César de María, Celeste Viale, Alonso Alegría, Sara Joffré. Vale la pena hacer notar que, si bien el teatro de grupo en el Perú está mermado —y en peligro de extinción- como dinámica para la creación perdurable en el tiempo/ espacio, sigue siendo un catalizador fundamental para la construcción de nuevas dramaturgias.

Entonces, la convergencia explosiva de ausencias, fracturas y violencia desmedida son el embrión de una inusual generación de dramaturgos peruanos nunca antes registrada en nuestra historia. Las hipótesis son interminables. Las razones, un misterio. Lo importante es que este 
hecho comprobable muestra un gran momento para el teatro peruano. Sin embargo, pese a que aún se está investigando este fenómeno, la nueva dramaturgia del cambio de siglo está en proceso de consolidarse y de abrir camino fuera de nuestras fronteras. ¿Será este el «momento» para (re)formular la pregunta que, en 1974, se hiciera Sara Joffré de «si existe un teatro peruano»?

\section{Mundos fantásticos, mundos posibles}

Para hablar de la dramaturgia peruana de estas dos últimas décadas, habría que situarnos en contexto. El declive de las ideologías - simbolizada en la caída del muro de Berlín- abrió camino a un protagonismo de lo individual que terminó por desacreditar la creación colectiva o la esperanza de lo grupal. Por otro lado, la aparición de internet y las nuevas tecnologías dieron paso a un complejísimo aparato de información que ha devenido en la decadencia de una jerarquía de valores reemplazada por una cultura del caos. Estos nuevos escenarios han provocado una exacerbación en el tiempo. Parece interesarnos solo el presente. El aquí y ahora. La idea del pasado está condenada al olvido y el futuro como proyecto es inestable. El tiempo ha sido reducido a un presente inmediato. Se ha fragmentado como mi idea de patria. La diferencia entre la sabiduría y la ignorancia es tener una opinión, diría Platón. Tener una opinión es tener una idea, y las ideas (o ideales) siempre construyen. Un país que no se piensa está condenado a seguir siendo isla. Lejos de su propia esencia y de su ombligo multicolor. Por lo tanto, no es extraño encontrar en la nueva dramaturgia peruana familias quebradas en su estructura de relaciones, padres ausentes y un hedonismo que nos separa del otro para centrarse en los deseos propios e incuestionables de un sujeto que solo busca su libertad individual. ¡A cualquier precio! Obviamente este último concepto hedonista está ligado al cinismo, no solo como una disposición para poner en duda la sinceridad y la bondad humanas, sino para expresar su inconformidad a través de la ironía y el sarcasmo. Daré dos ejemplos. En el caso de Tiernísimo animal, de Juan Carlos Méndez (1976), los personajes giran alrededor de Emmanuel, creador absoluto de un mundo imaginario llamado Ugbe. Desde ahí, él domina, controla y escapa de su realidad para esconder el sufrimiento de una relación romántica a punto de quebrarse. Es su lugar de poder. Su universo individual adonde nadie puede acceder. Ahí se oculta y se muestra a la vez. Se muestra siempre con sarcasmo y desprecio hacia cualquier situación que amenace o ponga en descubierto su inevitable caída. Ugbe es el símbolo del mundo que se derrumba y que se aísla, y en el que solo cabe una persona: Emmanuel. Nombre que por cierto significa en hebreo "dios-con-nosotros". La otra obra a la que quiero referirme es Dulces sueños, de Ruth Vásquez (1977). Allí sucede algo 
similar en tanto se construyen y deconstruyen mundos imaginarios que giran alrededor de un personaje atormentado en su relación con el entorno. Atenea es una niña de cinco años que no puede dormir porque la visitan fantasmas. Su tío la toca. La madre y el padre están ausentes. El hermano siente celos de ella. Un hada le trae chocolates. Gladys es su mejor amiga. Ambas descubren su sexualidad mientras la culpa parece estar más cercana a la muerte irremediable. En esta habitación se funden la fantasía y la realidad. Es complejo saber dónde ubicarse. Los personajes siempre deambulan en zonas desconocidas. Aparecen y desaparecen con la misma ironía que los hace dejar la infancia y enfrentarse a la muerte de aquello que no los deja crecer.

\section{Palabras urgentes que no llegan}

Es interesante notar que la tendencia - y de ello también soy partees que los escritores de esta generación tenemos la urgencia de escribir y montar nuestros textos en el menor tiempo posible. Esa urgencia refleja además el sentimiento de frustración y angustia que acompaña a los personajes de los nuevos creadores y que se convierte en una constante en la escritura dramática de nuestra generación. Sin duda, ese «sentimiento» responde a las secuelas de la guerra interna y al desarraigo que vivimos en nuestra infancia y adolescencia. Aquello podría ser una razón importante por la que no nos gusta hablar de ciertos temas referidos a nuestra historia y elegimos hablar de lo más inmediato, de lo que nos pasa ahora, de nuestra relación primero con nosotros mismos y luego - tangencialmente- con los demás. Roberto Ángeles dice en la introducción de su libro Dramaturgia peruana:

Se han producido tan pocas obras sobre este tema [Sendero, violencia interna] en esta nueva generación de dramaturgos, que ha crecido, que ha vivido su niñez o adolescencia en medio de esta guerra. Imagino que puede ser simplemente un factor de salud mental el olvidarse de esa etapa lo más pronto posible y recuperar la alegría que dicho contexto nos quitó. ¿A quién le provoca escribir una obra sobre un periodo tan doloroso de la historia del Perú? ¿Quién iría a ver una obra así? (Ángeles 2001: 12).

Vale la pena - a modo de ilustrar aquello a lo que me refiero- nombrar la obra Entre dos luces, de César Bravo (1960), en la que podemos observar la confrontación de un joven estudiante militante de la izquierda radical y subversiva, y una joven estudiante de la izquierda legal y moderada. Los personajes, como símbolo de la polaridad de la época, están atravesados por un tercero: el profesor. Una suerte de fuerza contradictoria que los arrastra a accionar o a quedarse sentados en sus ideas de 
cambio. Lo interesante es que esta obra fue leída públicamente en 1992 y puesta en escena en 1996 por la controversia que generó. Percy Encinas escribió la presentación para su publicación en la revista Muestra:

El autor recuerda que aquella vez, en la sala del Teatro Británico, Entre dos luces produjo en un asistente (conspicuo teatrista, por lo demás) una reacción de impugnación ideológica, de señalamiento absurdo, de desaforado intento deslegitimador al tema y al modo empleados en la obra, que ahora, en perspectiva, solo sazona el anecdotario de excesos pasionales que las piezas teatrales a veces han generado en quienes pretenden prescribir recetas unívocas de hacer arte. Sirva este recuerdo solo para ilustrar el contexto de tensión y hasta peligro en el que los artistas e intelectuales debían moverse para expresar sus ideas sobre el periodo de subversión armada y antisubversión (Encinas 2008: 3).

Cabe añadir que, a fines de 2009, cuando propuse a un grupo de estudiantes poner Entre dos luces en una breve temporada, las primeras reacciones fueron de abierta desconfianza. Felizmente se hizo y aquel conspicuo teatrista al que se refiere Percy Encinas no tardó en hacer algún comentario poco feliz.

\section{Relaciones peligrosas con salida conformista}

Frente a la ausencia de temas que nos acerquen a una reflexión más profunda de nuestra realidad, hay otros que sí forman parte vital y recurrente de la escritura dramática del cambio de siglo y que están referidos a los fenómenos sociopolíticos de los que venimos hablando. Encuentro temas comunes. No grandes historias y mucho menos trágicas. Personajes que viven en un permanente estado de malestar con ellos mismos y con el entorno que los rodea. Una suerte de deseo incompleto, a veces desesperado. Es común encontrar, por otro lado, parejas que se conforman desde un estado de fragilidad o con ciertos acuerdos de libertad. Nos hemos alejado de los grandes romances que son capaces de dar la vida por el otro o de atravesar mil peripecias para consumar su amor. Romeo y Julieta ya no son un ejemplo. En la dramaturgia actual estas relaciones son más prácticas. Incluso frías. Los temas de identidad sexual parecen llevar la posta en muchos casos y permiten entrever el despertar a nuevas conciencias sobre género y diversidad. Entre los más representativos dramaturgos que abordan estos universos tenemos a Eduardo Adrianzén, Gonzalo Rodríguez Risco, Roberto Sánchez Piérola, Jaime Nieto, Mariana de Althaus, Aldo Miyashiro, Juan Manuel Sánchez y Daniel Dillon. En realidad, hay muchos más. Cada uno, a su aire, circula en estos territorios de complejos vínculos afectivos poniendo como protagonistas a personajes muy jóvenes. Edades por cierto cercanas a las suyas. Pondré un par de ejemplos. En 
Demonios en la piel: la pasión según Pasolini, de Adrianzén (1964), todos los personajes se cuestionan su edad. Los más jóvenes quieren crecer y los más viejos quieren juventud. Tienen una conciencia extrema de sus propias edades y entran en conflicto con aquello que «deben hacer». Se relacionan afectiva e íntimamente sin importar las consecuencias y son capaces de poner a prueba su propia sexualidad. En todas las edades hay fuerzas que colisionan, parece decirnos la obra. Esa tensión que genera la oposición, en tanto fricciona con su otredad, nos muestra un camino de nuevas certezas. Y finalmente cualquier aproximación a una certeza nos da tranquilidad. $O$ desconcierto, si preferimos el vértigo creativo. En la obra Asunto de tres, de Rodríguez Risco (1972), la estructura dramática está compuesta por tres escenas, tres monólogos, un prólogo y un epílogo. Configuración que observamos también en obras de César de María y Mariana de Althaus, por ejemplo, que denotan dinámicas estructurales para componer pequeñas historias que muestran universos aislados que en algún punto se cruzan. En Asunto de tres las historias son sencillas y complejas a la vez. Sencillas en el relato y complejas en aquello que esconden las relaciones de los personajes, todos alrededor de los 30 años o menos. Aquí vemos cómo esos vínculos se arman y desarman según sus deseos más inmediatos. El sentido del deber también aparece como un imperativo. En la dramaturgia del cambio de siglo no existen los héroes $y$, por lo tanto, tampoco los antihéroes. Sin embargo, constantemente se ironiza sobre ellos. Aquí cabe resaltar que también lo fantástico y lo apocalíptico acompañan muchas de las obras compuestas por esta generación: Zoelia y Gronelio, de María Teresa Zúñiga; Super Popper, de César de María; Unicornios, de Aldo Miyashiro; o Cacúmenes, de Alejandro Alva, son algunos ejemplos. El tono escatológico de estas y otras obras de similares universos son reflejo de la impotencia del decir sesgado, controlado o simplemente del no decir, y se abre como signo de esperanza de una voz que empieza a levantarse de su propia pacatería para adoptar una postura más frontal y menos tímida.

Como vemos, las características de esta nueva dramaturgia están más centradas en el individuo inconforme con su entorno, en sus vínculos siempre tensos, en su búsqueda de una identidad que más bien lo diferencie del otro. Como mencioné anteriormente, los dramaturgos crean mundos sin héroes en donde el sentido del deber se ve cuestionado. Parece que el miedo al cambio es un fantasma que persigue. El cambio de siglo asusta. Este país asusta. Amar y dejarse amar ya no son palabras de aliento. A pesar del pesimismo, nuestros dramaturgos están creciendo y creando un nuevo mundo de posibilidades para habitarse y habitar con el otro. 


\section{Mapeo estadístico para no morir de pena}

Ahora, y para finalizar, quisiera hacer con ustedes un ejercicio estadístico que nos permita observar por qué se piensa que la nueva dramaturgia peruana tiene un número de representantes nunca antes registrado en nuestra historia teatral. En primer lugar, los concursos. Desde 1996 el Icpna organiza el Festival de Teatro Peruano-Norteamericano, un festival competitivo que lleva 11 ediciones. Las propuestas de dramaturgia peruana alcanzan casi el $90 \%$ frente a las de dramaturgia estadounidense. Cada año se reciben entre 40 y 50 proyectos. El IPAE convocó, en 1999, otro concurso de obras de teatro y se presentaron 70 textos. Luego, en 2007, el Teatro Británico organizó el Primer Concurso de Dramaturgia Peruana y se recibieron 89 proyectos. Al margen del incentivo económico, es importante darnos cuenta de que los escritores o el interés por escribir está creciendo considerablemente.

Por otro lado, tenemos las publicaciones. Tres antologías fundamentales del desaparecido Teatro Nacional (1999, 2000, 2001), que además fue motor central de la gestación del concurso del Icpna antes mencionado y de varias iniciativas que definitivamente intentaron (y lo hicieron) darle una mirada al teatro de todo el Perú. Ruth Escudero estuvo a la cabeza. Las interesantes publicaciones de Dramaturgia peruana, de Roberto Ángeles (1998, tomo I, y 2001, tomo II) y la última sobre Dramaturgia de la historia del Perú (2006). En 2010, la Ensad nos sorprendió con dos antologías de las obras de sus dramaturgos escritas durante seis décadas. No podemos dejar de mencionar el invaluable aporte que realiza Sara Joffré en su revista Muestra, que ya ha publicado 23 ediciones desde 2000. Ello significa más de 40 textos dramáticos de jóvenes escritores que quieren y necesitan un espacio más allá de los protocolos editoriales. La gran mayoría de textos han sido puestos en escena. En el campo de la investigación, Alfredo Bushby - también dramaturgo- publicó un amplio estudio sobre este tema en el libro Románticos y posmodernos. La dramaturgia peruana del cambio de siglo (2011).

No hay duda de que el Perú es un país centralista y que su historia se escribe siempre desde la capital. Un espejismo con sabor extranjero que nos viene como camisa de fuerza desde la Colonia. Costa, sierra y selva se miran de lejos con extrañeza. Pero, felizmente, y repito, el teatro es desconcierto. En 2000 conocí las Muestras de Teatro Peruano. Fue la primera vez que mi grupo — recién fundado— salía de Lima. Espacio Libre llegaba a Arequipa. Se mezclaba con grupos de todas las regiones. ¡Había teatro en el Perú! Para nuestra pequeña cabeza limeña, era difícil imaginarlo.

¿Esto qué tiene que ver con lo anterior? Mucho. Porque así como existen concursos, publicaciones y grandes plataformas para el teatro en la 
capital, y esa figura hegemónica predomina en el pensamiento colectivo de los artistas peruanos, hay otro teatro que se mueve y se busca a sí mismo. Aquí coexisten las muestras, los encuentros universitarios y los festivales de teatro escolar que promueven la dramaturgia de autores peruanos. Son espacios de intercambio, trueque y convivencia de materiales que, al ser exhibidos, generan contagio e interés multiplicador. También se conocen y gestan nuevas grupalidades que se arriesgan a escribir, adaptar y componer escenarios para ese teatro que parece olvidarlos. Ello también merece una estadística. Un mapeo concienzudo de sus rutas y necesidades. A simple vista $-\mathrm{y}$ gracias a nuestros recorridos como grupo- hay mucho por documentar sobre la nueva dramaturgia peruana. Podemos notar la clara influencia de los grupos emblemáticos y de los autores, no solo limeños, que a lo largo de cuatro décadas han dejado semillas de su trabajo.

Es verdad que en gran medida se responsabiliza a la capital de desatender el interior, pero creo que esa responsabilidad es compartida y debe dejar de ser culposa. En fin, se abre una puerta para otro diálogo. Lo importante, frente a este notable crecimiento de la escritura teatral, es que no dejemos de preguntarnos: «¿Y dónde está el Perú?». Hacer es recordar. $Y$ recordar es hacer para no repetir errores:

No recuerdo. No tengo memoria, y por ende no tengo iniciativa: no hago historia. No hago la historia que me corresponde. He gastado más energía en olvidar que en recordar. Sé que he olvidado muchas cosas porque tengo las huellas impregnadas en mi conducta, pero no tengo recuerdos, no tengo memoria. Mis recuerdos son, fundamentalmente, ejercicios de imaginación. Soy un peruano ilustrado, de a pie, pero ilustrado, $y$ he sido formado para tener conciencia de mi historia y de mi diario quehacer, pero, ya ven, he transformado mis recuerdos en fantasías, en leyendas, en mentiras, y mi diario vivir no tiene la conciencia que requiere el avance de mi historia: un paisaje (Ángeles 2006: 7).

Este es solo el comienzo de un largo camino en nuestra historia como teatro peruano. Tenemos suficiente evidencia de que se está escribiendo. Ahora nos toca prestar más atención y difundir aquello que -aunque falta consolidarse - nos va marcando un camino para la reflexión y la investigación. 


\section{REFERENCIAS BIBLIOGRÁFICAS}

ADRIANZÉN, Eduardo (2009, febrero). Demonios en la piel: la pasión según Pasolini. En Muestra, nro. 19.

ALVA, Alejandro (2008). Cacúmenes. Manuscrito inédito.

ÁNGELES, Roberto (2001). Dramaturgia peruana Il. Lima: edición del autor.

ción del autor. (2006). Dramaturgia de la historia del Perú. Lima: edi-

BRAVO, César (2008, mayo). Entre dos luces. En Muestra, nro. 17.

BUSHBY, Alfredo (2011). Románticos y posmodernos. La dramaturgia peruana del cambio de siglo. Lima: Fondo Editorial de la Pontificia Universidad Católica del Perú.

DE MARÍA, César (2007). Superpopper [título primigenio Super Popper]. Salidas de emergencia. Lima: Solar Ediciones.

ENCINAS, Percy (2008, mayo). «Presentación». En Muestra, nro. 17.

MÉNDEZ, Juan Carlos (2002, junio). Tiernísimo animal / La luz de la lluvia. Muestra, nro. 9.

MIYASHIRO, Aldo (2004). Unicornios. Manuscrito inédito.

RODRÍGUEZ RISCO, Gonzalo (2008, octubre). Asunto de tres. En Muestra, nro. 18.

VÁSQUEZ, Ruth (2001, mayo). Dulces sueños. En Muestra, nro. 5.

ZÚÑIGA NORERO, María Teresa (2004). Teatro, memoria y herencia. Huancayo y Minnesota: Ideologies \& Literature. 